САБИРОВА Нагима Садыковна - кандидат политических наук, Московский государственный областной университет (141014, Россия, Московская обл., г. Мытищи, ул. Веры Волошиной, 24; snagima95@gmail.com)

\title{
КОНЦЕПЦИЯ РОССИЙСКОЙ ПРАВОВОЙ СИСТЕМЫ КАК ЗАЛОГ РАЗВИТИЯ ПОЛИТИЧЕСКОЙ КУЛЬТУРЫ ДЕМОКРАТИЧЕСКОГО ТИПА
}

\begin{abstract}
Аннотация. В данной статье рассматривается правовая система современной России, фундаментом которой является ее Конституция. В соответствии с ее нормативно-правовыми актами, в основе которых заложены демократические принципы защиты прав человека и гражданина, с положительной динамикой формируется и политическая культура демократического типа. Автор приходит к выводу, что в ходе исторически долгого процесса становления правовой государственности сегодняшняя Россия имеет в этом направлении наращенную базу систем и знаний. Их функциональная продуктивность зависит как от властных структур, так и от самих граждан, которые в последние годы, по наблюдениям, осуществляют все более демократическую модель поведения.
\end{abstract}

Ключевые слова: правовая система, правовое государство, политическая культура, демократия, Конституция, культурные ценности, концепция, традиции, общество, государство, гражданин

3 аконодательная система занимает ключевую позицию в любом государстве. Ее стержневой функцией является обустройство государства, охрана и защита установленного им порядка и режима. Также очевидно, что закон представляется верховенством государства независимо от его политического режима, т.к. закон стоит на страже интересов властных структур и предписан, как было уже указано, ими же. Исходя из этого, важно подчеркнуть, что автор данной статьи рассматривает законотворчество как аспект, влияющий на политическую культуру общества, и залог реализации поставленных властью задач. Уникальна история формирования Российского государства, событийность которого богата такими вехами, как самодержавие, тоталитаризм и начало социализма. В свою очередь, социализм кардинально сменяют новые рычаги власти и направления либерально-демократической формы, которая сформировала правовую систему современной России, получившую статус правового государства. Следует отметить, что правовое государство как теоретическая концепция и соответствующая практика имеет долгую и поучительную историю, корни которой уходят в античную эпоху.

Сам термин «правовое государство» утвердился в первой трети XIX в. в немецкой юридической литературе. В дальнейшем он получил широкое распространение, в т.ч. и в России, где среди видных сторонников теории правового государства были Б.Н. Чичерин, Б.А. Кистяковский, П.И. Новгородцев и др. Сформировавшиеся различные концепции, выражавшие идею, смысл и понятие правовой государственности, говорили о становлении и развитии нового (антифеодального) юридического мировоззрения, утверждении идей гуманизма, принципов равенства и свободы всех людей, поисках различных государственно-правовых средств, направленных против узурпации публичной политической власти ${ }^{1}$.

Существование правового государства в современном мире определяется конкретными его принципами, где точкой опоры является верховенство права,

1 Концепции и характеристики правового государства. Доступ: https://infopedia. su/17x749d.html (проверено 29.10.2021). 
что обеспечивает равноправие всех перед законом независимо от социального положения и занимаемой должности, национальности, расы и вероисповедания. Основываясь на защите прав и свобод человека и гражданина, сама государственная власть строится на принципе разделения властей, т.е. власть подчиняется предусмотренным требованиям права. Также задействована правовая форма взаимоотношений индивида, общества и государства, строящаяся на взаимности прав и обязанностей. Этими принципами руководствуется и современное российское правовое законодательство.

Статья 1 Конституции Российской Федерации гласит: Российская Федерация - Россия есть демократическое федеративное правовое государство с республиканской формой правления ${ }^{1}$. Статья 10 предусматривает, что государственная власть в Российской Федерации осуществляется на основе разделения на законодательную, исполнительную и судебную. Органы законодательной, исполнительной и судебной власти самостоятельны ${ }^{2}$. В п. 1 ст. 17 говорится, что в Российской Федерации признаются и гарантируются права и свободы человека и гражданина согласно общепризнанным принципам и нормам международного права и в соответствии с настоящей Конституцией.

В правовой системе России Конституция признается верховным правовым актом. Она имеет высшую юридическую силу, прямое действие и применяется на всей территории России. Законы и иные правовые акты не должны противоречить Конституции РФ (п. 1 ст. 15 Конституции РФ). Все акты, изданные в РФ, в субъектах РФ и на территориях местного самоуправления должны соответствовать федеральной Конституции. Органы государственной власти, органы местного самоуправления, должностные лица, граждане и их объединения обязаны соблюдать законы (п. 2 ст. 15 Конституции РФ). К числу актов, которые должны соответствовать законам, относятся нормативные правовые акты Президента и Правительства РФ, российских министерств, федеральных служб, агентств и др. Есть точка зрения, что «в советское время сила закона подменялась “ведомственным нравом”, построенным на личных контактах и “телефонном праве”, но главной альтернативой закону являлась коммунистическая воля, выраженная в партийных директивах коммунистической партии» ${ }^{3}$. Естественно, советское законодательство было обрамлено несгибаемой идеологией строительства коммунизма, но это отдельная большая тема.

Один из важнейших аспектов формы правового государства - это либерально-демократический механизм выстраивания отношений между государством и обществом, который в идеале формирует политическую культуру демократического типа внутри страны. Как известно, во многих демократических государствах есть свои ценности и свои символы демократии. Тем не менее политическая культура демократического типа, как полагает автор, имеет единые ключевые признаки, первый из которых - приверженность законам, а вектор координации общества направлен на такие демократические ценности, как права и свободы человека и гражданина. Вторым признаком считается массовое участие общества в политической жизни страны, чувство ответственности граждан за свой политический выбор и способы его осуществления. Эти

\footnotetext{
1 Конституция РФ. Ст. 1. Доступ: http://www.consultant.ru/document/cons_doc_ LAW_28399/b57f514e606ee66a6f97d072551b16a416610dfc/ (проверено 29.10.2021).

2 Конституция РФ. Ст. 10. Доступ: http://www.consultant.ru/document/cons_doc_LAW_28 399/5fc039bb7454flaf7eba9238d9b35574d81dd447/ (проверено 29.10.2021).

3 Россия - правовое государство. Доступ: https://studme.org/97750/pravo/rossiya pravovoe_gosudarstvo (проверено 29.10.2021).
} 
главные правовые постулаты представляются базовыми механизмами правовой системы демократического государства.

Россия, как и другие страны, имеет свой собственный менталитет и ценности, свою глубокую историю становления как мощного централизованного государства, которое и сейчас продолжает переживать модернизацию в контексте либерально-правовых форм после распада СССР. Суть этой модернизации состоит и в том, чтобы сохранить в глобализационной гонке мировой цивилизации богатое культурное наследие России, ценности которого безмерны. Они выражаются и в силе государства, и в глубине нравственных устоев, и в чертах характера как русского человека, так и всего многонационального народа РФ, что всегда помогало России выстоять перед лицом врагов и сохранить свою целостность.

Русский философ и мыслитель В.С. Соловьев писал: «Право возникает фактически в истории человечества наряду с другими произведениями общечеловеческой жизни, каковы язык, религия, художество и т.д. Все эти формы, в которых живет и действует душа человечества и без которых немыслим человек, как такой, очевидно, не могут иметь своего исторического начала в сознательной и произвольной деятельности отдельных лиц, не могут быть произведениями рефлексии, все они являются сперва как непосредственное выражение инстинктивного родового разума, действующего в народных массах; для индивидуального же разума эти духовные образования являются первоначально не как добытые или придуманные им, а как ему данные. Это несомненно фактически, какое бы дальнейшее объяснение мы ни давали самому духовному инстинкту человечества» [Соловьев 2014: 523]

Традиционные и культурные ценности наполняют духовное сознание и влияют на его формирование в обществе. Граждане современной России с их обогащенным потенциалом и образованностью вполне могут иметь интерес к законодательству, защищающему их человеческие и гражданские права. Следует отметить, что за последние годы российское общество изменилось: оно больше тяготеет к либеральным формам жизни, и, конечно, в этом чувствуется участие уже выросшего молодого поколения, которое владеет и пользуется правами, закрепленными в Конституции РФ. В этом случае именно оно - держатель новой политической культуры демократического типа, а правовая система является проводником в становлении этой политической культуры.

Еще в начале XXI в. А.А. Галкин и Ю.А. Красин писали, что в России развертываются процессы, формирующие демократическую культуру. Во-первых, происходит осознание, что демократия не тождественна сложившемуся в 1990-е гг. режиму и группам правящей элиты, которые называли себя «демократами». Это способствует возрождению оценки демократии как положительной и политически мобилизующей идеи. Во-вторых, через практику «дикого рынка» происходит осознание отсутствия автоматической связи между рыночными и демократическими преобразованиями и открывается возможность превращения демократии в цементирующее ядро общественно-политических отношений, не сводимое только к рыночным реформам. В-третьих, демократические процедуры становятся неотъемлемым элементом общественно-политического образа жизни народа, к которому общество быстро привыкает [Галкин, Красин 2003: 237-238].

Многие ученые полагают, что для России самой подходящей политической культурой является гражданская культура, которая будет носить смешанный характер. По их мнению, такая культура не отметает традиции, но это тоже отдельная и большая тема. Может возникнуть вопрос, разве политическая 
культура демократического типа не располагает правом выбора и сохранности традиций? Главная цель, как видит автор, не потерять свои корни, демократия же по своей конструкции не может стать для этого преградой. В этом случае можно привести в пример размышления Е.Г. Ясина: «Если в России, как и в большинстве других стран, действует эволюционная парадигма - закономерность развития культуры от простого к сложному, которая в мире до сих пор работает безотказно, для нас демократия только начинается» [Ясин 2005].

В данное время в России наблюдается положительная динамика восприятия правовой системы, элементы которой располагают к становлению политической культуры с демократическими принципами. Ощутимо и влияние правовой системы России на вовлечение россиян в борьбу с явлениями, которые подрывают веру в правосудие и равенство прав человека и гражданина.

Несколько лет назад в своей книге Б.А. Исаев и Н.А. Баранов писали, что в России большинство населения, понимая необходимость неких общих правил, готово соблюдать законы, но только при условии соблюдения законов представителями органов власти. Однако российская практика последних лет свидетельствует о грубейших нарушениях российского законодательства чиновниками различных рангов, проявляющихся в появлении «оборотней в погонах», в коррупционных скандалах, затрагивающих все органы государственной власти и органы местного самоуправления [Исаев, Баранов 2013: 243].

В своих работах автор часто отмечает особый характер российского народа, пережившего множество перемен и сопутствующие им глобальные вызовы. Народ сумел сохранить ценности и веру в будущее. Теория правового государства выделяет форму власти как его охранную силу и защитника общественных интересов, что обязывает власть в подтверждение своей функциональной подлинности быть заинтересованной в доверии своих граждан. В ином случае это отступление от принятых законодательных правовых концепций.

Таким образом, современная российская правовая система имеет либерально-правовой характер, консолидирующий общество и власть и ценности прав человека и гражданина. Процесс становления правовой государственности однозначно требует длительного времени, и сегодняшняя Россия в этом направлении имеет достаточную базу систем и знаний. При усилии властных структур и не без участия граждан, которые в последние годы, по наблюдениям, реализуют более демократическую модель поведения, Россия может твердо встать на платформу правового государства и тем самым выстроить вектор становления политической культуры демократического типа.

\section{Список литературы}

Галкин А.А., Красин Ю.А. 2003. Россия: Quo vadis? М.: Изд-во ИС РАН. 276 с. Исаев Б.А., Баранов Н.А. 2013. Современная российская политика: учебное пособие для бакалавров. СПб: Питер. 443 с.

Соловьев В.С. 1914. Собрание сочинений: с 3 портретами и автографом (под ред. и с примеч. С.М. Соловьева, Э.Л. Радлова). СПб: Книгоиздательское товарищество «Просвещение». Т. 8.722 с.

Ясин Е. Г. 2005. Приживется ли демократия в России? М.: Новое издательство. 384 с. 
SABIROVA Nagima Sadykovna, Cand.Sci. (Pol.Sci.), Moscow Region State University (24 Very Voloshinoj St, Mytishchi, Moscow Region, Russia, 141014; snagima95@gmail.com)

\title{
THE CONCEPT OF THE RUSSIAN LEGAL SYSTEM AS A GUARANTEE FOR THE DEVELOPMENT OF A DEMOCRATIC POLITICAL CULTURE
}

\begin{abstract}
The article examines the legal system of modern Russia, the foundation of which is its Constitution. In accordance with its normative legal acts, which are based on the democratic principles of protecting human and civil rights, a political culture of a democratic type is being formed with positive dynamics. The author also concludes that during the historically long process of establishing legal statehood, today's Russia has an increased base of systems and knowledge in this direction. Their functional productivity depends both on the power structures and on the citizens themselves, who in recent years acquire an increasingly democratic model of behavior.

Keywords: legal system, legal state, political culture, democracy, Constitution, cultural values, concept, traditions, society, state, citizen
\end{abstract}

